\begin{tabular}{lccr} 
A R C H I V E & O F & M E C H A N I C A L & E N G I N E E R I N G \\
\hline VOL. LXII & 2015 & Number 1
\end{tabular}

10.1515/meceng-2015-0006

Key words: FPGA, control system, mechatronics, fatigue test, strain energy parameter

WOJCIECH MACEK * EWALD MACHA **

\title{
THE CONTROL SYSTEM BASED ON FPGA TECHNOLOGY FOR FATIGUE TEST STAND MZGS-100 PL
}

The paper presents a solution of the control system for fatigue test stand MZGS-100 PL, comprising the integrated Real-Time controller based on FPGA (FieldProgrammable Gate Array) technology with LabVIEW software. The described control system performs functions such as continuous regulation of speed induction motor, measuring strain of the lever machine and the test specimen, displacement of the polyharmonic vibrator, as well as the elimination of interferences, overload protection and emergency stop of the machine. The fatigue test stand also allows to set the pseudo-random history of energy parameter $W(t)$.

\section{Introduction}

The construction and effectiveness of control systems for fatigue test stands are closely connected with the development of computers, increasing their speed of work and computing performance. Continuous improvement of measurement techniques and control methods are also noticeable in fatigue tests of material science. Tests of materials are heading not only to wide characterization of their mechanical properties, but also to precise reproducing of real service loadings in engineering structures. Therefore, it appears necessary to build specialized fatigue machines to test materials under multiaxial loadings with variable courses in time, and then to verify formulated mathematical models for lifetime prediction of the constructed elements.

The described, specialized machine for fatigue tests MZGS-100 PL is a part of mechatronic system to test specimens of structural materials under bending, torsion or proportional combination of these loadings. This fatigue

* Alstom Power, Thermal Power, Thermal Services, Fabryczna 10, 53-609 Wrocław, Poland; E-mail: wojciech.macek@alstom.com

** Department of Mechanics and Machine Design, Faculty of Mechanical Engineering, Opole University of Technology, Mikołajczyka 5, 45-271 Opole, Poland 
test stand was built in the Department of Mechanics and Machine Design, Opole University of Technology, Poland, and it is legally protected by the law of the Polish Patent Office [1, 2].

The realisation of polyharmonical loading in MZGS-100 PL is the sum of four harmonic components which have different amplitudes, frequencies and phases, and these are set by the machine operator. In this machine, the loadings are generated by the polyharmonic inertial vibrator with four disks. It is possible to determine combination loading with eccentric inertial weights fixed on rotational disks.

To the present time, a few solutions of control systems for MZGS-100 PL machine have been applied $[3,4,5]$. In [5] the authors describe advantages and disadvantages of the four options of control systems based on: (i) data acquisition board AMBEX with $\mathrm{C}++$ environment, (ii) data acquisition board Daqboard/2000 and LabVIEW environment, (iii) data acquisition board NI PXI-6259 and LabVIEW environment, and (iv) programmable logic controller SAIA PCD2.

The aim of this paper it to eliminate weaknesses of the previously used four options of the control system and to present a new solution based on NI cRIO-9074 controller by using FPGA technology, performing parallel calculations in a fatigue test process control.

\section{Connection of the control system with fatigue machine}

The fatigue test stand MZGS-100 PL (Fig. 1) is composed of three-phase induction motor $0.18 \mathrm{~kW}$, for operation at variable frequencies and in difficult conditions caused by the oscillatory motion of the polyharmonic vibrator. Controlling signals are sent to the motor through the frequency converter Altivar 28.

The described control system performs functions such as continuous regulation of speed induction motor, measuring strain of the lever machine and the test specimen, displacement of the polyharmonic vibrator, as well as the elimination of interferences, overload protection and emergency stop of the machine.

On the machine lever, there are affixed four active strain gauges forming a full bridge, which are used for determination of the stresses $\sigma(t)$ in the specimen. Non-contact measurement of displacement of the lever machine is used for determination of the strains $\varepsilon(t)$ of the specimen.

The measuring signals from the strain gauge bridge, on the lever of loading specimen, after amplification by the amplifier type ZEPWN CL 100P) $(0-10 \mathrm{~V})$, are read through the analog input module NI 9215 of NI cRIO-9074 controller, and after scaling by the software represent the stresses $\sigma(t)$. 
THE CONTROL SYSTEM BASED ON FPGA TECHNOLOGY FOR FATIGUE TEST STAND..

The signals from the non-contact displacement inductive sensor Turck (0-10 V) are also read by the analog input module the NI 9215, and after scaling become equal to the strains $\varepsilon(t)$ of the specimen.

In order to scale the system and to directly measure the strain $\varepsilon(t)$, it is necessary to affix additional strain gauges on the specimen, which are connected to the module NI 9237 strain gauge bridge, integrated with the NI cRIO-9074.

The third module used in the controller NI cRIO-9074, is an analog output module NI 9263, sending the control signal to the frequency converter Altivar $28(0-10 \mathrm{~V})$.

The controller NI cRIO-9074, which operates in the LabVIEW FPGA software, is connected over TCP/IP and works with PC (host) with an operating system LabVIEW Real-Time.

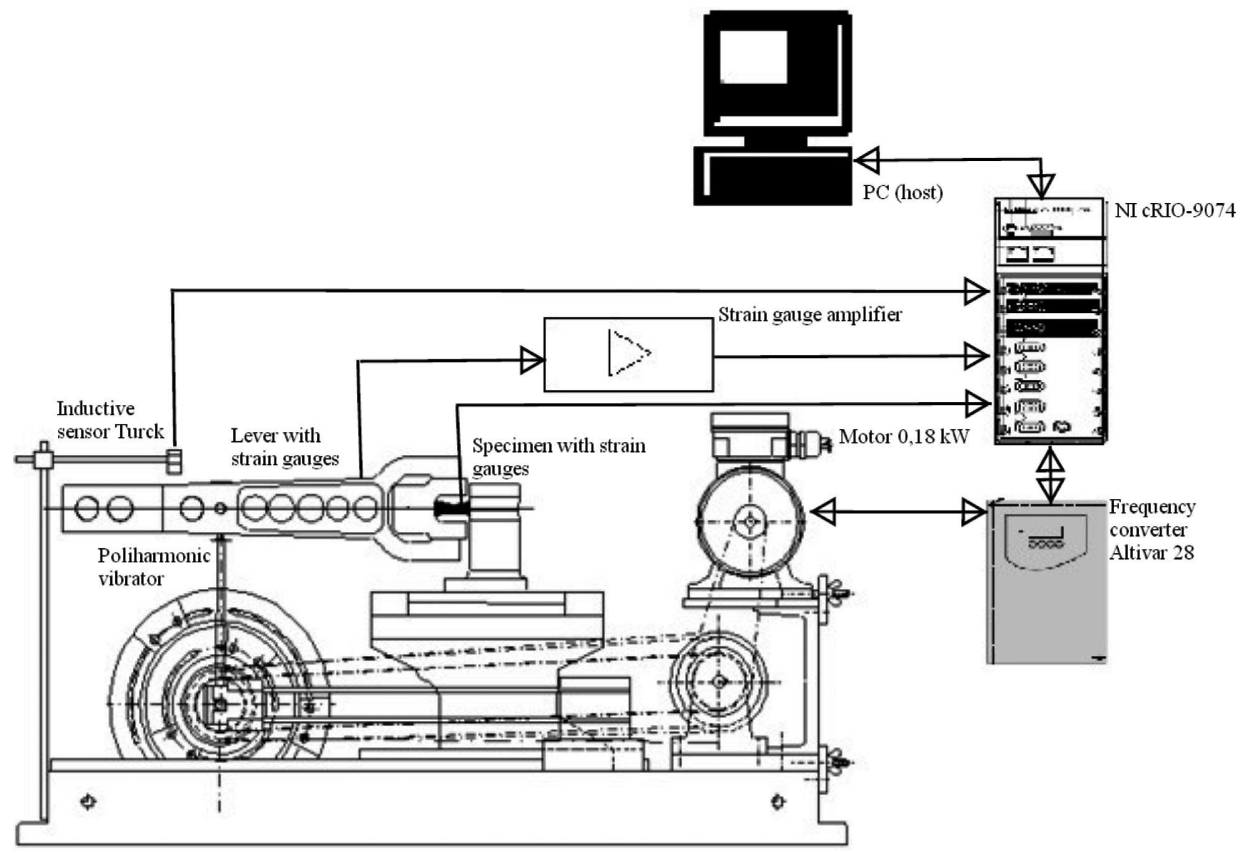

Fig. 1. Control system for the fatigue test stand MZGS-100 PL

\section{Construction and principle of operation of the fatigue machine MZGS-100 PL}

Figure 2 shows perspective drawings (from the side and from the top) of the considered fatigue test stand. Two holders (9) are applied for fastening of the specimen (1). One of them is joined in the articulated way with the lever (4), and the other one is stiffly joined with the column (5) on the machine 
body (7). The lever (4) is joined in the articulated way with the tie (10) which is connected to the polyharmonic vibrator (11). The electric motor (6) drives the polyharmonic vibrator (11) through the intermediate shaft (14). The electric motor (6) is controlled by the system, that is described in more detail in the next chapter.

a)

b)

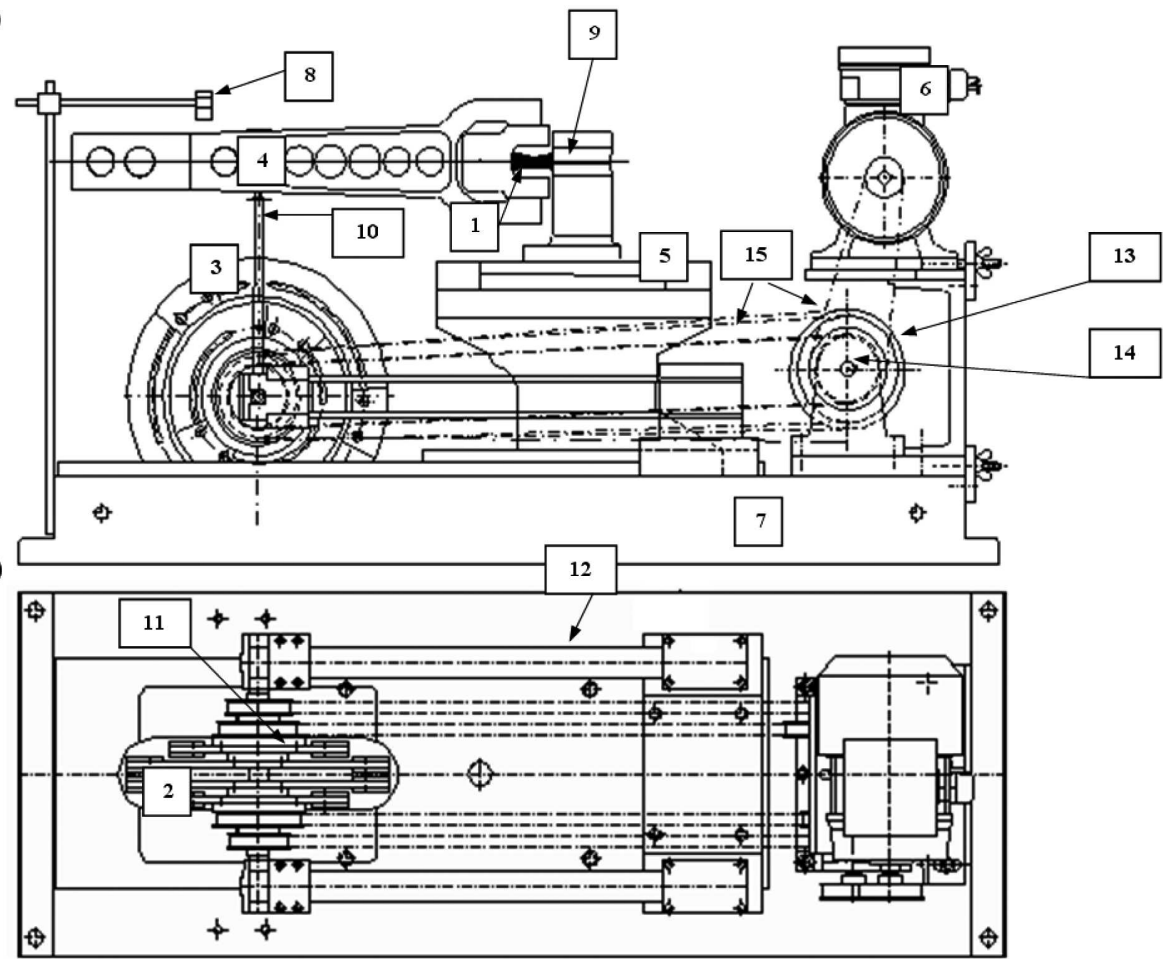

Fig. 2. The fatigue test stand MZGS-100 PL: a) from the side, b) from the top (without elements $4,5,8,9) ; 1$ - specimen, 2 - disks for load application, 3 - weights, 4 - lever with strain gauges, 5 - rotational column, 6 - motor $230 \mathrm{~V}, 7$ - machine base, 8 - inductive senor, 9 - holders for a specimen, 10 - tie, 11 - polyharmonic vibrator, 12 - flat springs, 13 - gear, 14 - intermediate shaft

The polyharmonic vibrator includes four disks (2) fixed with the rolling bearings on the shaft. Four flat springs (12) provide elastic connection between the vibrator and the machine body. Loading is realized by the weights (3), which are eccentrically mounted on rotational disks.

Five gear wheels (13) are mounted on the intermediate shaft (14). At the lever (4), there are the strain gauges joined with the conditioning card DBK 16 with the amplifier. The required stress is obtained in the specimen by suitable set-up of the rotational column (5); the angle $\alpha=0$ corresponds to bending, the angle $\alpha=\pi / 2$ means torsion, and each intermediate value of the angle $\alpha$ evokes a biaxial stress state generated by the simultaneous bending 
and torsional moments. The scheme of the specimen loading is presented in Fig. 3.

The values of the torsional moment $M_{s}$ and the bending moment $M_{g}$ loading the specimen are expressed by the following relation:

$$
\operatorname{tg} \alpha=\frac{M_{s}}{M_{g}} .
$$

The resultant moment is calculated from the following relation:

$$
M=\sqrt{M_{g}^{2}+M_{s}^{2}} .
$$
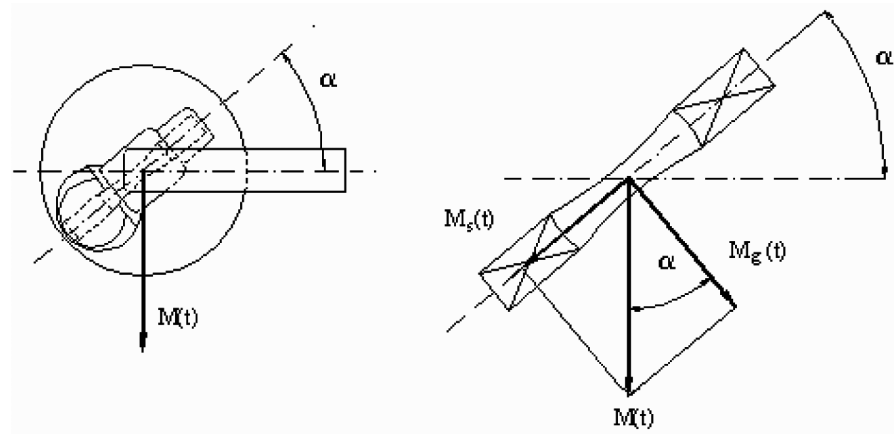

Fig. 3. Loading of the specimen

The weights located at the disks of the vibrator determine the component amplitude of vibrations of each disk. Amplitudes of the bending and torsional moments, $M_{g}$ and $M_{s}$, are equal to the product of the lever arm length $l$ (4 in Fig. 2) and the resultant inertial force $B$ of a set of weights attached to each disk:

$$
M_{a}=B l ; \quad \bar{B}=\bar{B}_{1}+\bar{B}_{2} .
$$

The resultant inertial force $B$ of each disk is equal to the product of the total mass $m$ of the weights attached to the disks, the radius $r$ of their position measured from the axis of rotation, a square of the angular velocity $\omega$ of the disk, and cosine of the angle $\delta$ of their spacing:

$$
B=0.5 m r \omega^{2} \sqrt{2(1+\cos \delta)} .
$$

Figure 4 shows a disk of the vibrator where the quantities appearing in Eq. (4) are included.

Before performing the fatigue tests, frequency of the motor rotations $f_{0}$ should be determined in the computer program for application of the motor 

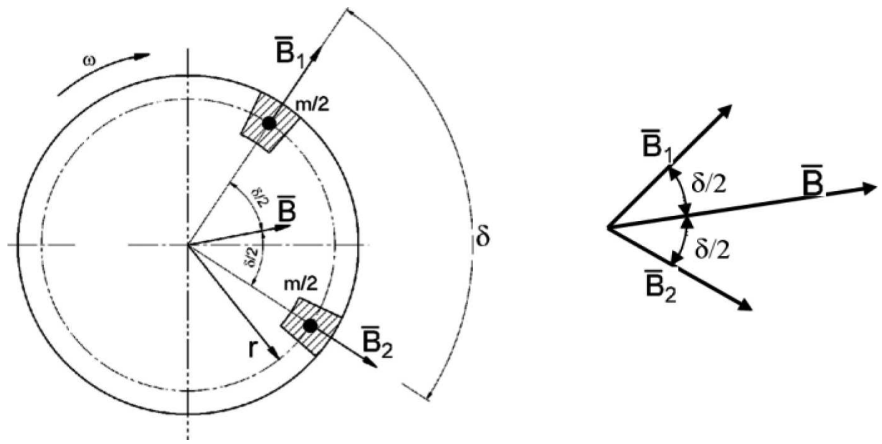

Fig. 4. A disk of the vibrator with the weights spaced at the angle $\delta$

speed. It is essential for determination of the centrifugal force generated by the masses located on the disks. When the overall dimensions of particular disks are known, the resultant moment $M(t)$ generated by four rotational disks of vibrator can be written as:

$$
M(t)=0.5 l \sum_{i=1}^{4} m_{i} r_{i} \omega_{i}^{2} \sqrt{2\left(1+\cos \delta_{i}\right)} \sin \left(\omega_{i} t+\varphi_{i}\right)
$$

where:

$m_{i}$ - unbalanced masses at disks,

$r_{i}$ - radiuses of mass distances from the axis of rotation,

$\omega_{i}-$ angular velocities of disks,

$\varphi_{i}-$ vibration shift phases,

$\delta_{i}-$ angles of mass spacing at disks,

$t$ - time.

Figure 5 presents polyharmonic loadings depending on the frequency of motor rotations, for $f_{0}=25 \mathrm{~Hz}, 30 \mathrm{~Hz}$ and $35 \mathrm{~Hz}$, when the masses of weights on particular disks of the polyharmonic vibrator were $m_{1}=m_{2}=m_{3}=m_{4}=$ $=87.01 \mathrm{~g}$.

The test stand MZGS-100 PL allows to:

A. Determine the energy fatigue characteristics of materials $\left(W_{a}-N_{f}\right)$ under cyclic: (A1) bending moment, (A2) torsional moment and (A3) any combined proportional bending and torsional moments;

B. Generate the pseudo-random loading with polyharmonic frequency spectrum for: (B1) bending moment, (B2) torsional moment and (B3) any combined proportional bending and torsional moments.

In the tests performed according to the variants of (A), the energy fatigue characteristics of materials $\left(W_{a}-N_{f}\right)$ is obtained, analogous to the standard characteristics of Wöhler $\left(\sigma_{a}-N_{f}\right)$ and Coffin-Manson $\left(\varepsilon_{a}-N_{f}\right)$. The tests performed by variants of (B) are used to verify different algorithms for the 
a) $\mathrm{M}(\mathrm{t})[\mathrm{Nm}]$

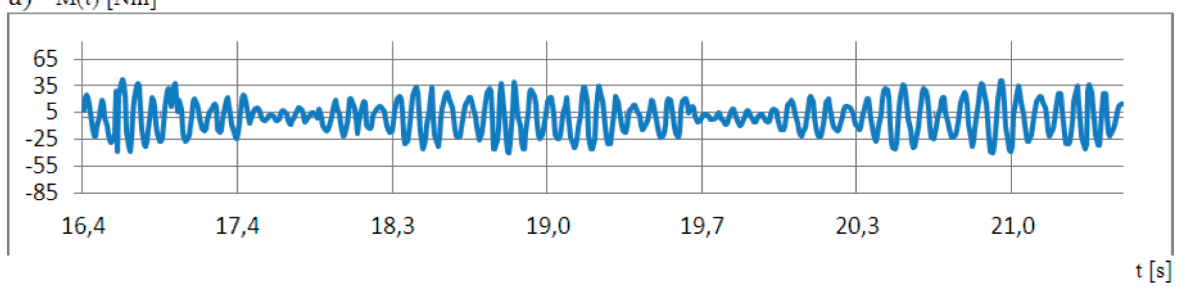

b) $\mathrm{M}(\mathrm{t})[\mathrm{Nm}]$

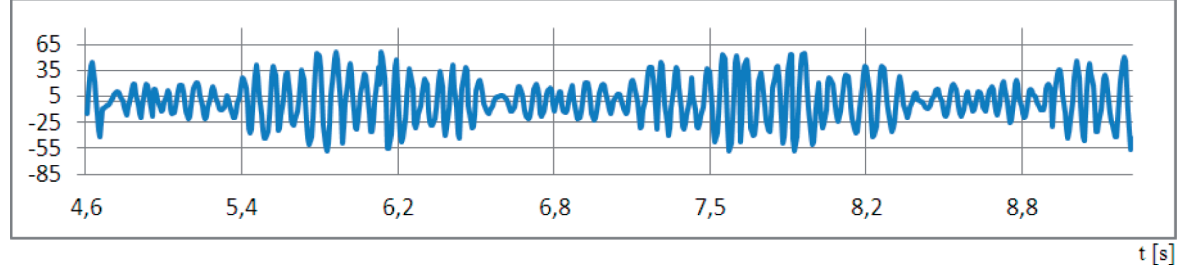

c) $\mathrm{M}(\mathrm{t})[\mathrm{Nm}]$

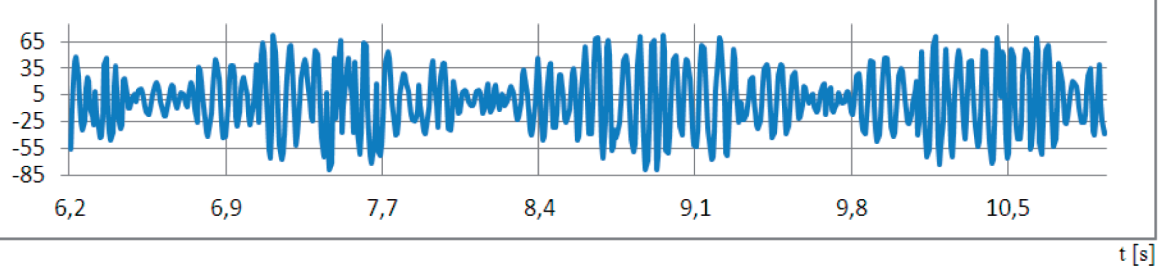

Fig. 5. Polyharmonic signals of the moment $M(t)[\mathrm{Nm}]$ with frequency of the motor rotations $f_{0}$ : a) $25 \mathrm{~Hz}$, b) $30 \mathrm{~Hz}$, c) $35 \mathrm{~Hz}$

assessment of fatigue life of materials under biaxial random loading [6, 7 , 8]. In tests with sinusoidal loads (A variants) the unbalanced mass is present only on one of the vibrator discs.

\section{Process control using the energy parameter $W(t)$}

Histories of the energy parameter $W_{g}(t)$ for bending are calculated as follows [9]:

$$
W_{g}(t)=0.5 \sigma(t)\left|\varepsilon(t)-\varepsilon_{i}^{p l}\right|
$$

where:

$\sigma(t)$ - realistic normal stress on the surface of a specimen under bending, $\varepsilon(t)$ - normal strain on the surface of a specimen under bending, $\varepsilon_{i}^{p l}=\varepsilon\left(t_{i}\right)$ while $\sigma\left(t_{i}\right)=0$ for successive $i=1,2,3, \ldots$ follows:

Histories of the energy parameter $W_{s}(t)$ for torsion are calculated as

$$
W_{s}(t)=0.5 \tau(t)\left|\varepsilon_{T}(t)-\varepsilon_{T i}^{p l}\right|
$$


where:

$\tau(t)$ - realistic shear stress on the surface of a specimen under torsion, $\varepsilon_{T}(t)=0.5 \gamma_{T}(t)$ - theoretical shear strain on the surface of a specimen under torsion,

$\varepsilon_{T i}^{p l}=\varepsilon_{T}\left(t_{i}\right)$ while $\tau\left(t_{i}\right)=0$ for the successive $i=1,2,3, \ldots$ (Fig. 6).

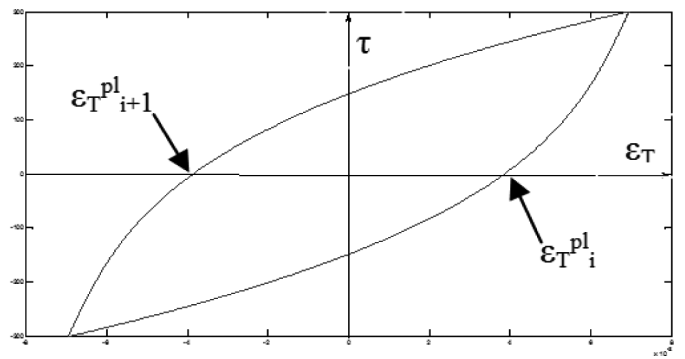

Fig. 6. Stress-strain hysteresis loop of material under torsion in the range of elastic-plastic deformation

The analog signal read from the strain gauge bridge fixed to the lever, after amplification, is proportional to the torsional moment $M_{s}(t)[\mathrm{Nm}]$. The measuring signal from a non-contact displacement inductive sensor Turck $(0-10 \mathrm{~V})$ or from additional strain gauges on the specimen, is scaled to shear strain $\varepsilon_{T}(t)[\% 0]$.

Nominal (pseudo-elastic) shear stress, $\tau_{n}(t)$, is calculated according to the following equation:

$$
\tau_{n}(t)=\frac{M_{s}(t)}{2 W}
$$

where: $W=\frac{\pi d^{2}}{32}$ is section modulus of torsion for specimen with diameter $d$.

Equation (8) is valid for elastic deformation range. In elastic-plastic deformation, the realistic amplitude of shear stress $\tau_{a}$ is smaller than the nominal one (pseudo-stress) $\tau_{n a}$ (Fig. 7).

The relationship $\tau_{a} \leq \tau_{n a}$ results from Ramberg-Osgood characteristic under torsion, and can be written as:

$$
\gamma_{\mathrm{a}}=\frac{\tau_{a}}{G}+\left(\frac{\tau_{\mathrm{a}}}{H^{\prime}}\right)^{\frac{1}{n^{\prime}}}
$$

where:

$\tau_{a}$ - realistic shear stress amplitude,

$\gamma_{a}$ - engineering total shear strain amplitude, 


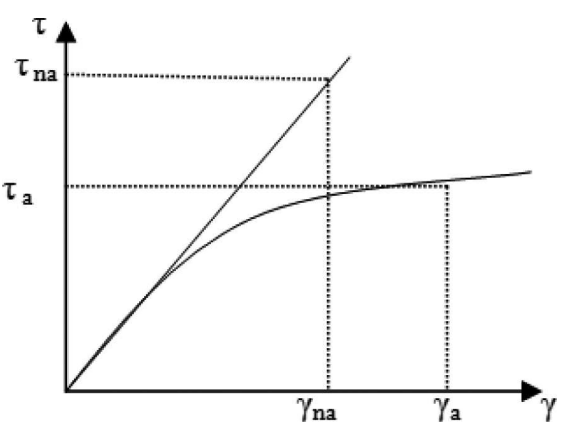

Fig. 7. Relationship, $\tau-\gamma$, for pseudo-elastic and elastic-plastic range of strain under torsion

$G$ - shear modulus,

$H^{\prime}$ - coefficient of cyclic strength,

$n^{\prime}$ - exponent of cyclic hardening.

To calculate the realistic shear stress amplitude, $\tau_{a}$, based on nominalshear stress amplitude $\tau_{n a}$, the energy relationship by Łagoda-Macha [10] was used:

$$
\frac{\tau_{n}^{2}}{2 G}=\frac{\tau_{a}^{2}}{2 G}+\frac{1-n^{\prime}}{1+n^{\prime}} \tau_{a}\left[\frac{\tau_{a}}{H^{\prime}}\right]^{\frac{1}{n^{\prime}}}
$$

In Eq. (9) the term raised to the power $\frac{1}{n^{\prime}}$ is equal to plastic shear strain amplitudes $\gamma_{a}^{p l}, \gamma^{\mathrm{pl}}$ which is measured during the experiment. For each hysteresis loop (Fig. 10), the following relationship is used:

$$
\left[\frac{\tau_{a}}{H^{\prime}}\right]^{\frac{1}{n^{\prime}}}=\gamma_{a}^{p l}=2 \varepsilon_{T j}^{p l}=2 \varepsilon_{T i+1}^{p l} .
$$

If we substitute Eq. (11) into Eq. (10), and perform analytical calculations, we will obtain dependence for the amplitude of realistic shear stress $\tau_{a}$ :

$$
\tau_{a}=\sqrt{\left(2 G \frac{1-n^{\prime}}{1+n^{\prime}} \varepsilon_{T}^{p l}\right)^{2}+\sigma_{n}^{2}}-2 G \frac{1-n^{\prime}}{1+n^{\prime}} \varepsilon_{T}^{p l} .
$$

In order to determine the fatigue characteristic of the material $\left(W_{a}-N_{f}\right)$, the specimens are tested at various load levels with a constant amplitude of the energy parameter $W_{a}$, and the number of cycles to failure $N_{f}$ is registered. The calculation of energy fatigue characteristics $\left(W_{a}-N_{f}\right)$ for bending is shown in [4]. 


\section{Control system based on NI cRIO-9074 Controller and LabVIEW FPGA}

The important element of this system is a programmable frequency converter Altivar 28 which converts one-phase voltage $230 \mathrm{~V}$ to three-phase voltage $230 \mathrm{~V}$ and supplies the inductive squirrel-cage motor $0.18 \mathrm{~kW}$. The frequency can be changed through control signal from analog output module NI 9263 of NI cRIO-9074 controller, or optionally, with potentiometer connected to analogue input frequency converter. Besides the frequency converter, in the circuit of Altivar 28 there is also a transmitter of error signals. The transmitter signal is used to the protection of the power system and in case of short-circuit or overload the motor will be turned off.

As described earlier and shown in Fig. 1, for connection in the NI cRIO9074 controller three I/O modules were used.

The measuring signals from the strain gauge bridge, on the machine lever, represent stresses $\sigma(t)$, and signals from non-contact displacement inductive sensor Turck $(0-10 \mathrm{~V})$ represent the strains $\varepsilon(t)$ of the specimen, and they are read by the analog input module the NI 9215.

For direct measurement of strain $\varepsilon(t)$, additional strain gauges on the specimen are used, which are connected to the module NI 9237 strain gauge bridge, integrated with the NI cRIO-9074 controller.

The analog output module NI 9263 sends the control signal to the frequency converter Altivar $28(0-10 \mathrm{~V})$.

The software system contains two main programs, such as the HOST interface in the Real-Time program to communicate with $\boldsymbol{F P G A}$ interface in LabVIEW FPGA.

The LabVIEW programme contains subVIs for reading, calculating and writing data in NI cRIO-9074 controller and PC hard disk memory for calculating stress, strain and energy parameter (described in chapter 4).

For LabVIEW FPGA software, the programmer creates a LabVIEW code, and then the software generates VHDL code and passes it to the Xilinx compiler. After that, the compiler synthesizes the VHDL and places and routes all synthesized components into a bitfile, and finally the program is downloaded to the FPGA in the NI cRIO-9074 controller. The application works with sampling rate of $2 \mathrm{kHz}$. SubVI for calculating realistic stress $\sigma_{a}$, has two inputs: nominal stress $\sigma_{n}(t)$ and plastic strain $\varepsilon_{i}^{p l}$ (Fig. 6). SubVI for calculating Energy Parameter $W_{g}(t)(6)$ has three inputs: strain $\varepsilon_{a}$, plastic strain $\varepsilon_{i}^{p l}$ and realistic stress $\sigma_{a}$.

In subVI for calculations and communications performed in the LabVIEW Real-Time program, the process variable adjusts and saves data into a file. 
THE CONTROL SYSTEM BASED ON FPGA TECHNOLOGY FOR FATIGUE TEST STAND...

Figure 8 shows the starting part of main loop of the HOST diagram, which initiates communication with $\boldsymbol{F P G A}$. FPGA Open VI Reference must be opened before the application can communicate between the host VI and the FPGA VI. Invoke Method Functions are used to download, abort, reset, and run the FPGA VI on the FPGA target, wait for and acknowledge FPGA VI interrupts, read and write DMA FIFOs. FrequencyCoercion.vi will calculate the rate closest to the desired rate that FPGA can produce based on the top-level clock frequency.DMACalcs.vi performs calculations needed to set up and perform DMA transfers.

Figure 9 shows the next part of the main loop of the HOST diagram responsible for reading, sending to $\boldsymbol{F P G A}$ and saving.

The read/write control (CheckLate block) is located inside the While Loop, which can control and monitor the data passed through the FPGA VI front panel. There are also two Case structures i.a. to save the data in the file.

The part of code from HOST is the fragment responsible for the control process (Fig. 10). The program controls the signals of variable-energy parameter by PID tool adjusting the voltage of analog output AO [V].

Currently, the Proportional-Integral-Derivative (PID) algorithm is the most common control algorithm used in industry.

The code for control process by PID inserted to Timed Loop contains Case Structure, While Loop and Flat Sequence Structure.

Save_crio.vi for saving measurement data and calculation results, saves the file in the NI cRIO-9074 controller memory, after clicking "SAVE" button on the HOST front panel. The file name ,crio_hour,minute_day,month,year.txt" is written with sampling speed of $2 \mathrm{kHz}$ (Fig. 11).

Save_crio.viconsists of blocks like Concatenate Strings Function which concatenates input strings and 1D arrays of strings into a single output string. There also occur Build Path and Strip Path functions. This subVI has four cases in Case Structure: "Create File", "Saving", "Close File", "Idle".

In Fig. 12 are presented histories of the energy parameter $W(t)$ from (1) start-up, through (2) steady state to (3) switch off of the fatigue stand test under cyclic loading. The graph shows how the engine accelerates to a given state of the process variable. 

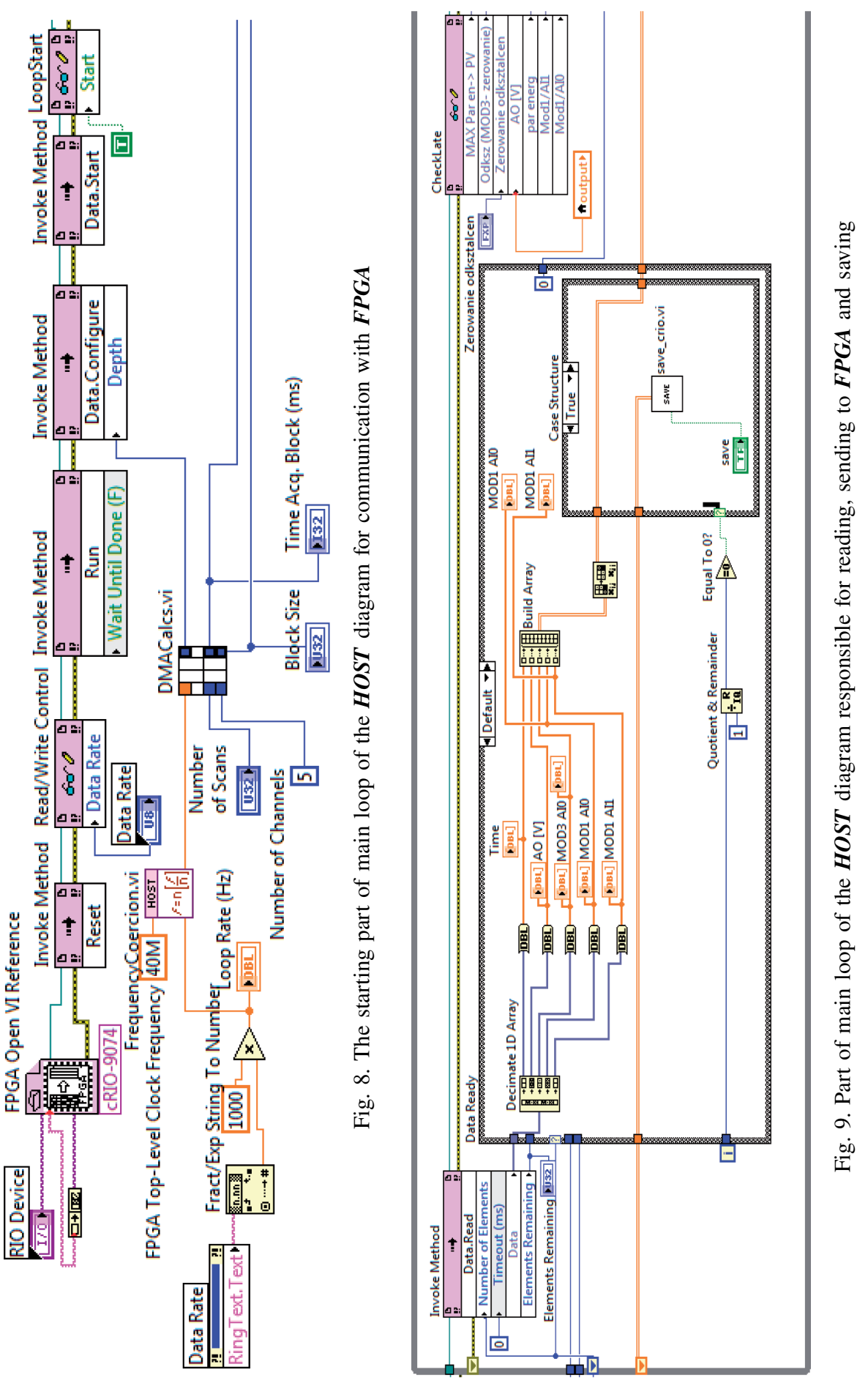

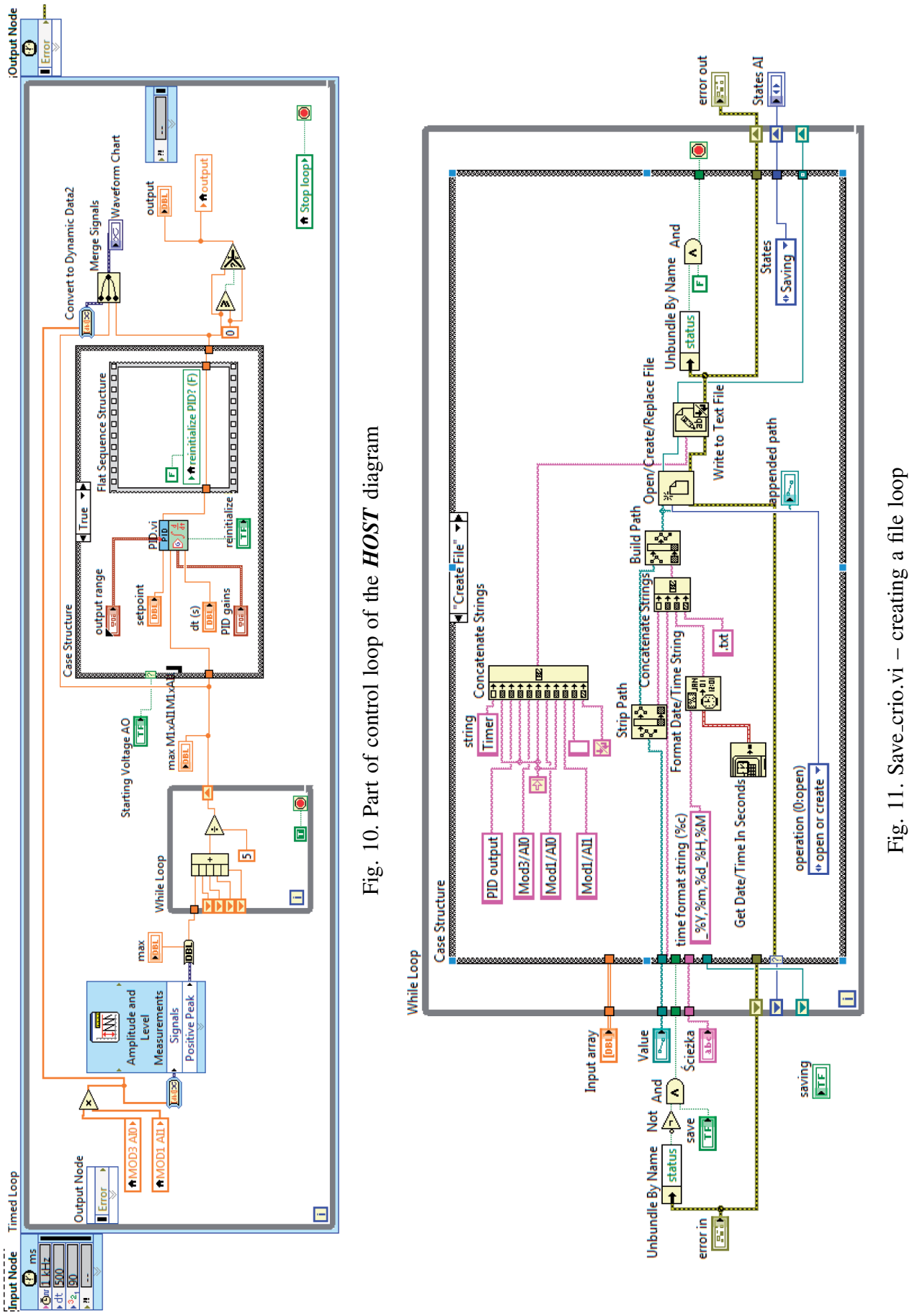


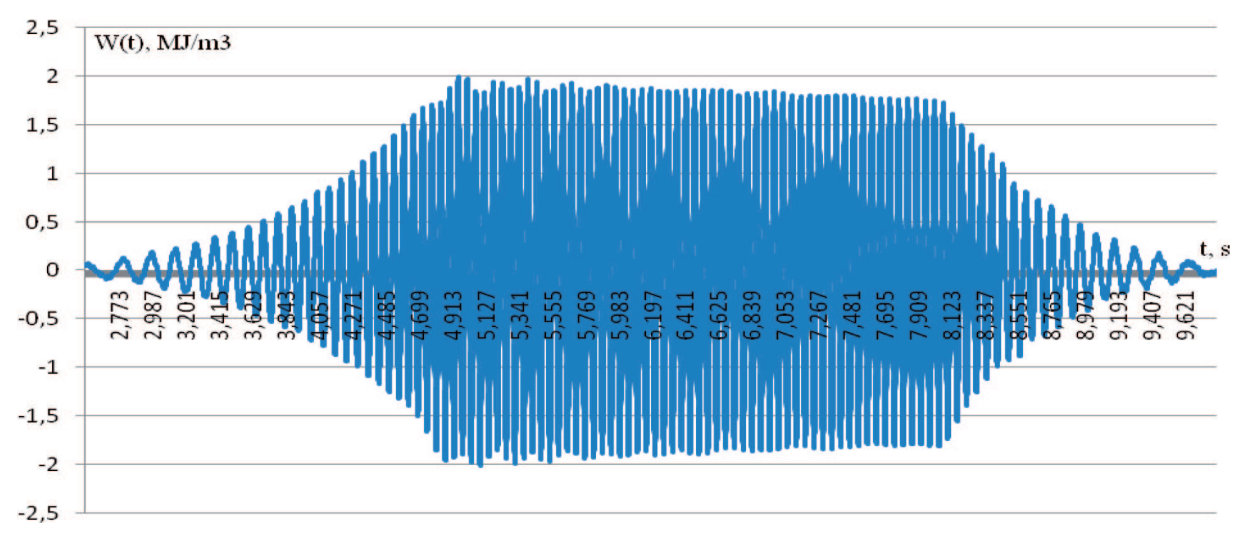

Fig. 12. History of the energy parameter $W(t)$ at start-up, steady state, and the machine switch off

\section{FPGA Technology}

Field-Programmable Gate Arrays (FPGA) are semiconductor devices based around a matrix of configurable logic blocks connected via programmable interconnects. Contemporary FPGAs have large resources of logic gates and RAM blocks to implement complex digital computations.

A hardware description language called the VHDL (VHSIC Hardware Description Language) is used to define the behavior of the FPGA.

To fulfill the requirements of operating conditions of the control process and data-processing systems, programmable arrays in LabVIEW 2011 FPGA Module were used. The use of FPGA technology [11] enabled the transfer of signal processing tasks to the layer of the hardware and, in this way the real time control system was relieved.

LabVIEW FPGA module provides a graphical programming approach that simplifies the task of interfacing to I/O and communicating data. Highlevel system design tools, like LabVIEW FPGA are used with National Instruments FPGA hardware products, built on a reconfigurable I/O (RIO) architecture.

In the discussed case, the LabVIEW environment facilitates the usage of energy parameter in controlling the process of loading of tested material and allows to compile the application to VHDL language.

\section{Conclusion}

The application of FPGA technology continues to increase as a highlevel tool developed to deliver the benefits of reprogrammable silicon chips to engineers and scientists at all levels of expertise in a variety of industries. 
The presented control system facilitates machine operation, registration of the measured data, performance and control of the fatigue tests. Creating new applications and simple modification of existing control programmes allow to perform parallel calculations in fatigue test process control, formulate and apply the parameters which characterize the fatigue properties of structural materials and then use them in the control system.

The main advantage of FPGA technology is that it extends the computing power of digital signal processors by breaking the paradigm of sequential execution, so that more tasks per clock cycle can be accomplished. Additional advantages are dynamically reconfigurable system and its simple recompilation.

Manuscript received by Editorial Board, September 16, 2014; final version, February 12, 2015.

\section{REFERENCES}

[1] Achtelik H.: A machine for fatigue tests under pseudorandom bending and torsion loading, Patent 158338, Polish Patent Office, Warsaw 1992 (in Polish).

[2] Achtelik H.: A device for fatigue tests under plane, non-synchronously variable stress state, Patent 366487, Polish Patent Office, Warsaw 2005 (in Polish).

[3] Macek W., Macha E.: Energy-saving mechatronic system forfatigue tests of materials under variable-amplitude proportional bending and torsion, Solid State Phenomena Vol. 164, 2010, pp. 67-72.

[4] Kasprzyczak L., Macha E., Marciniak Z.: Energy parameter control system of strength machine for material test under cyclic bending and torsion, Solid State Phenomena Vol. 198, 2013, pp. 489-494.

[5] Macek W., Macha E., Kasprzyczak L.: Variants of control mechatronic systems for fatigue tests of materials under variable-amplitude proportional bending and torsion, Transfer of Innovation to the Interdisciplinary Teaching of Mechatronics for the Advanced Technology Needs, Eds. E. Macha and G. Robak, Opole University of Technology, pp. 237-253, Opole 2009.

[6] Macha E.: A review of energy-based multiaxial fatigue failure criteria, The Archive of Mechanical Engineering XLVIII (1), 2001, pp. 71-101.

[7] Rozumek D., Marciniak Z.: Control system of the fatigue test stand for material test under combined bending with torsion loading and experimental results, Mechanical Systems and Signal Processing 22, 2008, pp. 1289-1296.

[8] Macha E., Niesłony A.: Critical plane fatigue life models of materials and structures under multiaxial stationary random loading: The state-of-art in Opole Research Centre CESTI and directions of future activities, International Journal of Fatigue, Vol. 39, 2012, pp. 95-102.

[9] Macha E., Słowik J., Pawliczek R.: Energy based characterization of fatigue behaviour of cyclically unstable materials, Solid State Phenomena Vols. 147-149, 2009, pp. 512-517.

[10] Słowik J., Lagoda T.: The fatigue life estimation of elements with circumferential notch under uniaxial state of loading, International Journal of Fatigue, Vol. 33, 2011, pp. 1304-1312.

[11] Sulaiman N., Obaid Z.A., Marhaban M.H., Hamidon M.N.: Design and implementation of FPGA-based systems - a review, Australian Journal of Basic and Applied Sciences, 3(4): 3575-3596, 2009. 
System sterowania maszyny do badań zmęczeniowych materiałów konstrukcyjnych typu MZGS 100-PL w technologii FPGA

\section{Streszczenie}

W pracy przedstawiono rozwiązanie układu sterowania maszyny zmęczeniowej MZGS-100PL, w oparciu o zintegrowany sterownik czasu rzeczywistego NI cRIO-9074 z oprogramowaniem LabVIEW w technologii FPGA. Przedstawiony układ sterowania umożliwia płynną regulację prędkości obrotowej silnika indukcyjnego, pomiar odkształceń dźwigni maszyny i badanej próbki, przemieszczenie wibratora poliharmonicznego, jak również eliminację zakłóceń oraz zabezpieczenie przed przeciążeniem i zatrzymanie awaryjne maszyny. Zaprezentowany system mechatroniczny do wyznaczania energetycznych charakterystyk zmęczeniowych materiałów przy zginaniu i skręcaniu pozwala na wyznaczanie energetycznych charakterystyk zmęczeniowych materiałów (Wa-N) przy obciążeniach cyklicznych oraz generowanie obciążeń pseudolosowych (poliharmonicznych). 